\title{
Segment Stock Market, Foreign Investors, and Cross-Correlation: Evidence from MF-DCCA and Spillover Index
}

\author{
Nan Xu and Songsong Li $\mathbb{D}$ \\ School of Management, Harbin Institute of Technology, Harbin, Heilongjiang, China \\ Correspondence should be addressed to Songsong Li; hitsongpie2019@163.com
}

Received 22 July 2020; Revised 26 August 2020; Accepted 9 September 2020; Published 23 September 2020

Academic Editor: Dehua Shen

Copyright ( $92020 \mathrm{Nan} \mathrm{Xu}$ and Songsong Li. This is an open access article distributed under the Creative Commons Attribution License, which permits unrestricted use, distribution, and reproduction in any medium, provided the original work is properly cited.

\begin{abstract}
Employing the tools of multifractal detrended cross-correlation analysis (MF-DCCA) and Diebold-Yilmaz spillover index (D.Y. spillover index), we examine the effect that the foreign investors have on the cross-correlations between the two-segment stock markets, that are the accessible and the inaccessible stock markets, and the other ten respective stock markets. The shares crosslisted by the same corporates on both the A-share and $\mathrm{H}$-share stock markets of China serve as the best sample to compile the two stock indices, which stands for the inaccessible stock market (AHA) and the accessible stock market (AHH), respectively. Empirical results show that the cross-correlations between the two-segment stock markets and the other ten pairs are multifractal, the multifractal strength of cross-correlations is stronger in AHH than AHA, and the intensified growth of the multifractal crosscorrelations in AHA can be seen as the increasing of the openness in the inaccessible market. The empirical result of D.Y. spillover index is consistent with the multifractal analysis above, and another interesting finding is that among the selected markets, the three markets with the strongest spillover effects with AHA and AHH are Taiwan, South Korea, and Singapore, respectively, and the weakest one is Australia during the sample scenarios.
\end{abstract}

\section{Introduction}

The cross-correlation (interdependence) of financial markets is always the subject of keen interest of financial economics [1], and an increasing number of research studies have been conducted on interdependence of stock markets. As we all know, the stock market is a nonlinear and complex dynamic system, and it exerts the significant influence on a country's economy; the intensive oscillations in stock markets may increase the uncertainty, and they even cause the successive devaluations of currencies and the collapse of the stock markets [2]. The violent fluctuations of the global stock markets during the period of extreme events, such as the global financial crisis, have caused varying degrees of damage to the economy of countries $[3,4]$. Therefore, it is very necessary to explore the reasons for the increased interdependence of global stock markets in terms of the academic value and the practical significance.
Nowadays, affected by the COVID-19 pandemic, the global financial markets are suffering the severe volatility; as the most influential stock market, the US triggered the circuitbreaker four times within 9 days, on March 9, March 12, March 16, and March 18 (local time), respectively, and then initiated several stock markets, including Canada, Brazil, South Korea, and Philippines, to activate the circuit-breaker, and the stock indexes of many countries have plummeted since March subsequently. The current complexity of global stock markets reminds us of the necessity and urgency of investigating the interdependence between stock markets and from which derives our research interest.

As for the cause of the cross-correlations between different stock markets, the two most popular views are the fundamentalinduced correlation and the investors-induced correlation. As discussed by Pindyck and Roremberg [5], stock prices of companies in unrelated lines of business move together in response to changes in current or expected future macroeconomic conditions. In the model of Mankiw, macroeconomic variables 
have decisive effects on comovements [6]. King and Wadhwani argued that most of the correlations in return are attributable to industry effects [7]. However, there are also some studies that find no evidence to support the fundamental-induced comovements. Karolyi and Stulz investigated the properties of cross-country stock return comovements, and the empirical results show that comovements between U.S. and Japanese share returns are not affected by the macroeconomic announcements significantly [8]. Also, Connolly and Wang identified that it is the foreign market return that exerts a dominant influence on the subsequent domestic market returns, while the economic fundamentals cannot contribute to the observed comovement of stock returns in the international equity markets [9].

Subsequently, more and more empirical results supporting the latter interpretation emerged which argue that transactions of investors strengthen the correlations between stock markets. Some studies analyze such subject based on the theory of the wealth effect. Kyle and Xiong supported that convergence traders' capacity of bearing risks reduces when they suffer trading losses, and their behaviors of liquidating positions in both markets result in the correlations increasing [10]. Yuan and Brunnermeier predicted that the correlations between different markets are stronger during downturns due to the wealth-constrained effect of investors $[11,12]$. Petmezas and Santamaria also provided evidence consistent with the wealth effect as a source of contagion for the majority of countries [13]. However, other researchers investigated the investorinduced correlations from the perspective of portfolio rebalancing. Hartmann used the nonparametric measure to study asset return linkages during periods of stress and found that the probability of crash in the stock market is twice as likely as the bond market, and during the crisis period, the evidence of "flight to quality" holds true due to the investors' transactions of portfolio rebalancing [14]. And Connolly also reported that the negative correlation of returns in the stock and bond market as the investors rebalance portfolios [15].

The unified conclusion is still not reached, though many studies conduct detailed analysis for the above two points of view. Thus, we focus on China's segment stock market with the unique institutional feature to investigate which of the reasons is valid in explaining the cross-correlations of stock markets: the segment stock markets of the accessible stock market in Hong Kong and the inaccessible stock market in the mainland China, which are two independent markets but with the different degrees of openness to foreign investors. While the previous studies in terms of the segment stock markets always focus on the matters of the phenomenon of different stock prices and the causes. Among them, most pay close attention to the segment stock markets of China's A-share and H-share markets [16-20], and several studies focus on the U.S. and the other markets [21-23]. However, different from above research studies, Richard analyzed the relationship of the segment stock market with the political risk [24]. Bekaert and Harvey assessed the impact of market liberalizations in segment equity markets of emerging countries [25]. In the most recent article closest to our research, Songsong $\mathrm{Li}$ and $\mathrm{Nan} \mathrm{Xu}$ et al. investigated the effect of international investors on the multifractal property in A-share and H-share markets in China, but there is no further exploration about the cross-correlation with the global stock market [26].

And different from the aforementioned studies, this paper expands the research scope of the existing literatures by exploring the extent of the role of foreign investors on the correlations between different stock markets utilizing the feature of the segment stock markets, the A-share and $\mathrm{H}$-share stock markets in China, which possess the differing degree of openness. The shares cross-listed in the accessible stock market in Hong Kong can be traded by the foreign investors freely, while the inaccessible one in the mainland of China is not open to foreign investors due to the strict restrictions on the transactions to foreign investors. The cross-listed shares listed in both the A-share and $\mathrm{H}$-share markets by the same corporates are exposed to the same underpinnings, making them the prime candidates to investigate which of the views mentioned above holds. To compile the two stock indices standing for the accessible market $(\mathrm{AHH})$ and inaccessible stock market (AHA), 71 shares cross-listed in both the A-share and $\mathrm{H}$-share markets are included to construct the desired indices by computing the capitalization-weighted average of those prices.

There was an important deregulatory reform in the stock market of China on November 17, 2014, called the ShanghaiHong Kong Stock Connect Program (SHSCP) during the period of our analysis, which permits foreign investors to purchase several stocks in the inaccessible stock market in Shanghai Stock Exchange through the Hong Kong Stock Exchange; such an event promotes us to investigate not only the differences in correlations in AHA and $\mathrm{AHH}$ with the world before SHSCP but to explore the changes in the correlation between the AHA and the global stock market after the stock market deregulation. The view of supporting that the fundamental underpinnings cause the correlations between countries holds when the results show that there are the similar cross-correlations with the worldwide in both AHA and $\mathrm{AHH}$, and also, there is no significant change of correlations with the world in AHA in the two subscenarios. Meanwhile, the differing degrees of correlations make another point holds true. And the previous studies paid close attention to the cross-correlations during the crisis period, while our study concentrates on the noncrisis period.

For the studies measuring the correlations (interdependence) between different stock markets, most of which are based on Efficient Market Hypothesis (EMH), employ the methods of econometric: GARCH [27-30], Copula [31-34], VAR [35-37], Markov switching model [38], and Pearson correlation coefficient [39]. However, the traditional methods based on the efficient market theory cannot describe accurately the change in the nonlinear, long-range, and complex dynamic stock markets involving multiple agents and affected by multiple factors [40]. Thus, the theory of Fractal Market Hypothesis (FMH) [41] emerged following the EMH, which provided the accurate evidence of the correlations from the perspective of econophysic, and heaps of research studies employ the econophysic method to investigate the correlations 
between different financial markets. As described by Ghosh, the multifractal detrended cross-correlation analysis (MF-DCCA) [42], the generalized DCCA [43], is a very rigorous and robust technique for assessment of cross-correlation between two nonlinear time series [44]; thus, a great number of studies employed such a tool to explore the cross-correlation of several fields, such as hydrological processes [45, 46], traffic signals [47], and geophysical data [48]. Thus, in this paper, we utilize the popular tool of MF-DCCA, to investigate the effect of the transactions of foreign investors. Also, the methods of the cross-correlation test and multifractal correlation coefficients matrices are employed to verify the interdependence of markets qualitatively and quantitatively. Moreover, a newly popular method of spillover index proposed by Diedold and Yilmaz $[49,50]$ is used to confirm our results further, which not only provides the magnitude of spillover indices between markets but the detailed directional spillover indices for each country. The results of the methods mentioned above are consistent in general, which verify that the combination of these methods is suitable and perfect to explore the interdependence of stock markets.

The structure of our research is as follows: Section 2 describes the methodology we employed; the sample data and descriptive statistics are shown in Section 3; Section 4 exhibits the empirical results; and the last part concluded.

\section{Methodology}

2.1. MF-DCCA. This multifractal detrended cross-correlation analysis (MF-DCCA) [42], a multifractal generalization of the seminal DCCA, was first developed by Podobnik [43], and the method can be described as follows:

(1) Suppose $\left\{x_{k}, k=1,2, \ldots, N\right\}$ and $\left\{y_{k}, k=1,2\right.$, $\ldots, N\}$ are two time series of length $N$, then the "profile" is determined as

$X(i)=\sum_{k=1}^{i}\left(x_{k}-\bar{x}\right), Y(i)=\sum_{k=1}^{i}\left(y_{k}-\bar{x}\right), \quad i=1,2, \ldots, N$,

where $\bar{x}=(1 / N) \sum_{k=1}^{N} x_{k}$ and $\bar{y}=(1 / N) \sum_{k=1}^{N} y_{k}$ is the mean of $\left\{x_{k}\right\}$ and $\left\{y_{k}\right\}$, respectively.

(2) Divide the new sequences $X(i)$ and $Y(i)$ into $N_{s}=$ $\operatorname{int}(\mathrm{N} / \mathrm{s})$ nonoverlapping windows of equal length $s$, in order to not discard any information of the sequence $X(i)$ and $Y(i)$, dividing them on the order of $i$ from small to large and from the opposite direction again, and we obtain $2 N_{s}$ segments totally.

(3) For every $s$ time scale in each segment $v\left(v=1,2, \ldots, 2 N_{s}\right)$, the least-square is used to fit the polynomial to get the local trend,

$$
\begin{array}{r}
x_{v}(i)=a_{1} i^{k}+a_{2} i^{k-1}+\cdots+a_{k-2} i+a_{k-1}, \\
y_{v}(i)=b_{1} i^{k}+b_{2} i^{k-1}+\cdots+b_{k-2} i+b_{k-1}, \\
i=1,2, \ldots, s ; k=1,2, \ldots
\end{array}
$$

(4) Then determine the variance.

For $v=1,2, \ldots, N_{s}$,

$$
F^{2}(s, v)=\frac{1}{s} \sum_{i=1}^{t}\left|X((v-1) s+i)-X^{v}(i)\right| \cdot\left|Y((v-1) s+i)-Y^{v}(i)\right|,
$$

And for $v=N_{s+1}, N_{s+2}, \ldots, 2 N_{s}$,

$$
\begin{aligned}
F^{2}(s, v)= & \frac{1}{s} \sum_{i=1}^{t}\left|X\left(N-\left(v-N_{s}\right) s+i\right)-X^{v}(i)\right| \\
& \cdot\left|Y\left(N-\left(v-N_{s}\right) s+i\right)-Y^{v}(i)\right| .
\end{aligned}
$$

(5) The $q^{\text {th }}$ order fluctuation function is

$$
F_{q}(s)=\left[\frac{1}{2 N_{s}} \sum_{v=1}^{2 N_{s}}\left[F^{2}(s, v)\right]^{q / 2}\right]^{1 / q} .
$$

In the formula (5), $q$ can take any real number but not zero; if $q=0$, fluctuation function can be rewritten as

$$
F_{0}(s)=\exp \left\{\frac{1}{4 N_{s}} \sum_{v=1}^{2 N_{s}} \ln \left[F^{2}(s, v)\right]\right\} .
$$

$F_{q}(s)$ serves as a function of the time scale $s$ and fractal order $q ; F_{q}(s)$ increases in a power-law relation with the increase of $s$,

$$
F_{q}(s) \sim s^{H_{x y}(q)} .
$$

The generalized Hurst exponent $H_{x y}(q)$, known as the generalized cross-correlation exponent, serves as the index to demonstrate whether the two series are multifractal crosscorrelation. When the value of $H_{x y}(q)$ is the function of $q$, the cross-correlation between them are multifractal; otherwise, it is monofractal. When the $H_{x y}(q)>0.5$, the crosscorrelation between two return series related to $q$ is longrange persistent and antipersistent between the two series when $H_{x y}(q)<0.5$. If $H_{x y}(q)=0.5$, there is no cross-correlation between them. Moreover, $H_{x y}(q)$ describes the scaling behaviors with large fluctuations for positive $q$, and on the contrary, for negative $q, H_{x y}(q)$ describes the scaling behaviors with small fluctuations, and the greater the range of the fluctuation of $H_{x y}(q)$, the stronger the multifractal cross-correlation between two series.

The relation between the generalized Hurst exponent $H_{x y}(q)$ and multifractal scaling exponent $\tau(q)$ can be given as

$$
\tau_{x y}(q)=q H_{x y}(q)-1 .
$$

The curvature of the line of $\tau_{x y}(q)$ and $q$ corresponds to the strength of multifractal cross-correlation.

Following the Legendre transformation, the singularity exponent $\alpha$ and the singularity spectrum $f(\alpha)$ can be obtained: 


$$
\begin{aligned}
& \alpha_{x y}(q)=H_{x y}+q H_{x y}^{\prime}(q) \\
& f_{x y}(\alpha)=q\left(\alpha_{x y}-H_{x y}(q)\right)+1
\end{aligned}
$$

The wider spectrum indicated a stronger degree of multifractal cross-correlation.

In order to measure the degree of multifractality, the financial risk measure $\Delta H(q)$ was proposed by Yuan et al. [51], as follows:

$$
\Delta H(q)=H_{\max }(q)-H_{\min }(q),
$$

where $\Delta H(q)$ is equal to the difference of $H_{\max }(q)$ and $H_{\text {min }}(q)$, and the lager value is, the stronger multifractal degree exists; thus, the greater is the risk in market and vice versa.

2.2. Diebold-Yilmaz VAR-Based Spillover Index. The Diebold-Yilmaz (D.Y.) spillover index is a new spillover index proposed by Diebold and Yilmaz [48, 49], which utilized the generalized VAR model of Pesaran and Koop [52, 53]. It excludes the dependence of the results on orthogonal order driven by Cholesky decomposition. The updated spillover method can not only analyze the total spillover effects but also the directional spillovers from/to a particular market.

The $N$-variable VAR $(p)$ process can be specified as

$$
x_{t}=\sum_{i=1}^{p} \Phi_{i} x_{t-i}+\varepsilon_{t}, \quad t=1,2, \ldots, T,
$$

where $x_{t}$ is an $N \times 1$ vector of return, $\varepsilon_{t}$ is a vector which follows independent and identical distribution with $\varepsilon_{i} \sim$ i.i.d. $(0, \Sigma), \Sigma$ is a covariance matrix, and $\Phi_{i}$ is an $N \times N$ matrix of coefficients.

And then, the above VAR process can be represented as a moving average representation process as $x_{t}=\sum_{i=0}^{\infty} \Theta_{i} \varepsilon_{t-i}$, and the $N \times N$ coefficient matrix $\Theta_{i}$ can be defined as $\Theta_{i}=\sum_{j=1}^{p} \Phi_{i} \Theta_{i-j}$, where $\Theta_{0}$ is an $N \times N$ identity matrix, and if $i<0, \Theta_{0}=0$. Moreover, spillover index is based on the generalized variance decompositions of Pesaran and Koop $[51,52]$. So, the forecast error matrix with an $H$-period horizon, $D^{H}=\left[d_{i j}^{H}\right]$, can de refined by

$$
d_{i j}^{H}=\frac{\sigma_{j j}^{-1} \sum_{h=0}^{H-1}\left(e_{i}^{\prime} \Theta_{h} \sum_{\varepsilon} e_{j}\right)^{2}}{\sum_{h=0}^{H-1}\left(e_{i}^{\prime} \Theta_{h} \sum_{\varepsilon} \Theta_{h}^{\prime} e_{j}\right)},
$$

where $\Sigma_{\varepsilon}$ is a variance-covariance matrix of the error $\varepsilon, \sigma_{j j}$ is the $j^{\text {th }}$ term on the diagonal of $\Sigma_{\varepsilon}$, and $e_{i}\left(e_{j}\right)$ is a selection vector with an $i^{\text {th }}\left(j^{\text {th }}\right)$ element equal to the unit and zero otherwise. The error terms are not orthogonal. Thus, the sum of the elements in each row of $d_{i j}^{H}$ is not equal to 1 : $\sum_{j=1}^{N} d_{i j}^{H} \neq 1$. To make use of the information available on invariance decomposition matrix to calculate the comparable magnitudes of the spillovers, Diebold and Yilmaz normalize the elements of $D^{H}$ as follows $[49,50]$ :

$$
\tilde{d}_{i j}^{H}=\frac{d_{i j}^{H}}{\sum_{j=1}^{N} d_{i j}^{H}} .
$$

${ }^{N}{ }_{\widetilde{H}}^{\text {This normalization }} \sim_{H}$ produces such properties as $\sum_{j=1}^{N} \tilde{d}_{i j}^{H}=1$ and $\sum_{i, j=1}^{N} \tilde{d}_{i j}^{H}=N$.

The total spillover index, $S_{\text {total }}^{H}$, which measures return spillovers of the global markets, is defined as

$$
S_{\text {total }}^{H}=\frac{\sum_{\substack{i, j=1 \\ i \neq j}}^{N} \tilde{d}_{i j}^{H}}{\sum_{i, j=1}^{N} \tilde{d}_{i j}^{H}} \times 100=\frac{1}{N} \sum_{\substack{i, j=1 \\ i \neq j}}^{N} \tilde{d}_{i j}^{H} \times 100 .
$$

Directional spillover of market $i$ received from all other markets $j\left(S_{i \leftarrow \bullet}^{H}\right)$ and transmitted to all other markets $j$ $\left(S_{\bullet \leftarrow i}^{H}\right)$ can be measured as followed:

$$
\begin{aligned}
& S_{i \leftarrow \bullet}^{H}=\sum_{\substack{j=1 \\
j \neq i}}^{N} \tilde{d}_{i j}^{H} \times 100, \\
& S_{\bullet \leftarrow i}^{H}=\sum_{\substack{j=1 \\
j \neq i}}^{N} \tilde{d}_{i j}^{H} \times 100 .
\end{aligned}
$$

\section{Data and Descriptive Statistics}

To investigate the effect that the foreign investors have on the cross-correlations between stock markets, we choose the sample of two stock indices from the segment stock markets (A-share and H-share) of China and the other ten respective stock indices of the global stock market-the U.S.'s S\&P500 Index (USA), U.K.'s FTSE100 (UK), France's CAC40 (FRA), Germany's DAX (GER), Taiwan's TWSE (TAI), Japan's Nikkei 225 (JAP), Korea's KOSPI (KOR), Thailand's SET (THAI), Singapore's Straits Times Index (SIN), and Australia's AS51 (AUS) from 01 January 2010 to 31 December 2019.

Since Chinese stock market does not provide the stock indices for cross-listed in the segment stock markets, we collect the daily closing prices of cross-listed shares of 71 companies listed and delisted after 01 January 2010 to compile the two indices, which cross-listed in the A-share market and the $\mathrm{H}$-share market, respectively. And during our sample period, there is a milestone event happened, the Shanghai-Hong Kong Stock Connect Program (SHSCP) on November 17, 2014, which splits the whole sample into the two subsamples to investigate the role of the foreign investors on cross-correlation between countries; the preperiod refers to the period from 01 January 2010 to the day before the SHSCP, and the period from the day of the SHSCP to 31 December 2019 denotes the postperiod.

We follow Nishimura [54] to compile the indices by calculating a capitalized-weighted average of stock closing prices for cross-listed stocks, and the index on day $t$ is computed as

$$
\operatorname{Index}_{t}^{m}=\sum_{l=1}^{71} \delta_{t}^{l(m)} p_{t}^{l(m)},
$$

where 


$$
\delta^{l(m)}=\frac{V_{t}^{l(m)} p_{t}^{l(m)}}{\sum_{l=1}^{71} V_{t}^{l(m)} p_{t}^{l(m)}} .
$$

In the expressions above, $p_{t}^{l(m)}$ is the price of stock $l$ in market $m$ ( $m=$ China mainland, Hong Kong) on day $t, V_{t}^{l(m)}$ refers to the number of shares of stock $l$ in the market $m$ on day $t$, and the return is calculated as $r_{t}=\ln \left(p_{t} / p_{t-1}\right)$, where $p_{t}$ is the closing index value at time $t$. Prices of cross-listed stocks on the A-share market and $\mathrm{H}$-share market and the number of shares were all retrieved from the Wind database.

The descriptive statistics of the return series for AHA, $\mathrm{AHH}$, and the other ten indices for the overall period are presented in Table 1. We can find that $\mathrm{AHH}$ is higher than AHA in terms of the values of maximum, minimum, and standard error, indicating that compared to AHA, the index return series of $\mathrm{AHH}$ fluctuates more fiercely; thus, the market risk is higher in AHH than AHA. We can also find that the mean of all indices return series are positive, and the skewness values of them in Table 1 are all different from and less than 0 , meaning that return series for the twelve indices are featured in a longer left tail than the right one. Moreover, the kurtosis values of all series during the sample period are greater than 3 significantly, thus indicating that the distributions are peaked with extreme values. Both the values of kurtosis and skewness reject the null hypothesis of Gaussian normal distribution, but with the distributions of asymmetric, fat-tailed, and non-Gaussian, and the J.B. statistic test also confirm this finding clearly (at a significance level of $1 \%$ ), which indicate that most series may present the features of long memory.

\section{Empirical Results}

4.1. Results of the Cross-Correlation Test and Coefficient Matrix. A new cross-correlation statistic proposed by Podobnik [43], similar to the Ljung-Box test [55], is employed to analyze the cross-correlation between AHA, $\mathrm{AHH}$, and the other ten indices return series qualitatively. The cross-correlation statistic between two series $\{x(i)\}$, $\{y(i)\}$ with the same length $N$ functions as follows:

$$
C_{i}=\frac{\sum_{k=i+1}^{N} x_{k} y_{k-i}}{\sqrt{\sum_{k=1}^{N} x_{k}^{2} \sum_{k=1}^{N} y_{k}^{2}}} .
$$

Then, the cross-correlation test statistic is

$$
Q_{c c}(m)=N^{2} \sum_{i=1}^{m} \frac{C_{i}^{2}}{N-i},
$$

which is approximately $\chi^{2}(m)$ distributed with $m$ degree of freedom. The cross-correlation test agrees well with the distribution of $\chi^{2}(m)$ if there is no cross-correlation between two-time series. The cross-correlation is significant if the cross-correlation test exceeds the critical value of the $\chi^{2}(m)$ distribution. Moreover, we describe the critical value of the $\chi^{2}(m)$ at $10 \%$ significance level with the degree of freedom varying from 1 to 1000 to test the cross-correlation qualitatively.
As we can see from Figure 1, the two subplots (a) and (b) show that the long-range cross-correlations existing in both AHA (the left one) and AHH (the right one) with the other ten indices return series at $10 \%$ level of significance over the entire sample period, and the stronger cross-correlation can be seen between AHH and other ten pairs than AHA's.

After testing the qualitative cross-correlations in the samples, we apply a new method, the multifractal correlation coefficients matrix, proposed by Podobnik [56] to verify the results above further, the function as follows:

$$
\rho_{\mathrm{DCCA}}=\frac{F_{\mathrm{DCCA}}^{2}(n)}{F_{\mathrm{DFA} 1\{n\}} F_{\mathrm{DFA} 2\{n\}}} .
$$

The value of $\rho_{\text {DCCA }}$ ranges between -1 and 1 when $\rho_{\text {DCCA }}$ equal zero means no cross-correlation between the two series, and the level of cross-correlation between positive and the negative case is split when $\rho_{\mathrm{DCCA}}$ takes the positive and negative value, respectively. We calculate the values of $\rho_{\text {DCCA }}$ based on different values of window size $s(s=16,32$, $64,128,256$, and 512) to analyze the time-varying crosscorrelations quantitatively. The larger time scales of $s$ correspond to the long-term interdependence between two series, while the small scales denote the short-term comovement, that is, contagion as we described. And the larger absolute value of $\rho_{\text {DCCA }}$ is associated with the stronger multifractal cross-correlation and vice versa.

Instead of presenting the values of each cross-correlation coefficients, we make this form of innovation, in which the size of the values corresponds to the depth of the color for each grid; the dark blue denotes the least values of crosscorrelation coefficients, the dark red stands for the maximum, and so on. Cross-correlation coefficients $\left(\rho_{\text {DCCA }}\right)$ matrices of AHA and $\mathrm{AHH}$ with the other ten stock indexes pairs with the different window sizes $(s=16,32,64,128,256$, and 512 days) are shown in Figure 2; the subplots (a) and (b) exhibit the empirical results for the preperiod and the postperiod, respectively, and in each subplot, $\rho_{\text {DCCA }}$ matrix of AHA and other ten pairs is shown on the upper, while the lower one is AHH's.

In the subplot (a), we can see the significant contrast in color between the matrices of AHA and $\mathrm{AHH}$, and the much dark color modules such as dark blue is associated with the lower values of $\rho_{\mathrm{DCCA}}$, which can be seen in most lattices of AHA's, showing that the multifractal correlation coefficients of AHA with the other ten pairs are much smaller than AHH's among all the different window sizes, which imply the stronger multifractal cross-correlation of $\mathrm{AHH}$ with the global stock market than AHA for the preperiod. While as for the different scales of correlation coefficients, we find that the much stronger correlations exist in the large time scales than the short scales, which correspond to the stronger longterm interdependence between stock markets but no contagion among these markets in the short-term period.

The calculation results of the cross-correlation coefficients $\left(\rho_{\mathrm{DCCA}}\right)$ after the SHSCP are presented in the subplot (b); we find that the comparison in color of matrices between AHA and AHH in the early stage tends to relax after the SHSCP, which denotes that the correlations between AHA, 
TABle 1: Descriptive statistics of the return series for AHA, AHH, and the other ten pairs for the overall period.

\begin{tabular}{lccccccc}
\hline & Mean & Maximum & Minimum & Std. dev & Skewness & Kurtosis \\
\hline AHA & $6.57 E-05$ & $3.49 E-02$ & $-8.64 E-02$ & $7.59 E-03$ & -0.7406 & 12.6715 \\
AHH & $8.67 E-05$ & $4.03 E-02$ & $-1.30 E-01$ & $8.09 E-03$ & -1.5908 & 32.9273 & $9437.571^{* * *}$ \\
USA & $1.72 E-04$ & $2.01 E-02$ & $-2.99 E-02$ & $4.05 E-03$ & -0.5789 & 7.6674 & $2221.959^{* * *}$ \\
UK & $2.83 E-05$ & $2.19 E-02$ & $-2.08 E-02$ & $3.99 E-03$ & -0.2193 & 5.6379 & $696.606^{* * *}$ \\
FRA & $7.13 E-05$ & $4.00 E-02$ & $-3.64 E-02$ & $5.25 E-03$ & -0.1865 & 7.6521 & $2147.278^{* * *}$ \\
GER & $1.37 E-04$ & $2.26 E-02$ & $-3.07 E-02$ & $5.13 E-03$ & -0.3263 & 5.8222 & $821.267^{* * *}$ \\
TAI & $5.03 E-05$ & $1.94 E-02$ & $-2.83 E-02$ & $4.01 E-03$ & -0.6491 & 7.1385 \\
JAN & $1.65 E-04$ & $3.23 E-02$ & $-4.84 E-02$ & $5.68 E-03$ & -0.5379 & 8.7415 & $1791.103^{* * *}$ \\
KOR & $6.43 E-05$ & $2.13 E-02$ & $-2.79 E-02$ & $4.03 E-03$ & -0.4767 & 7.3007 & $1859.629^{* * *}$ \\
THA & $1.36 E-04$ & $2.30 E-02$ & $-2.52 E-02$ & $4.09 E-03$ & -0.2728 & 6.9471 & $1479.908^{* * *}$ \\
SIN & $6.73 E-06$ & $1.43 E-02$ & $-1.91 E-02$ & $3.36 E-03$ & -0.3197 & 5.0626 & $448.831^{* * *}$ \\
AUS & $2.82 E-05$ & $2.29 E-02$ & $-2.50 E-02$ & $3.80 E-03$ & -0.3408 & 5.6551 & $730.146^{* * *}$ \\
\hline
\end{tabular}

Note. ${ }^{* * *} 1 \%$ significance level.

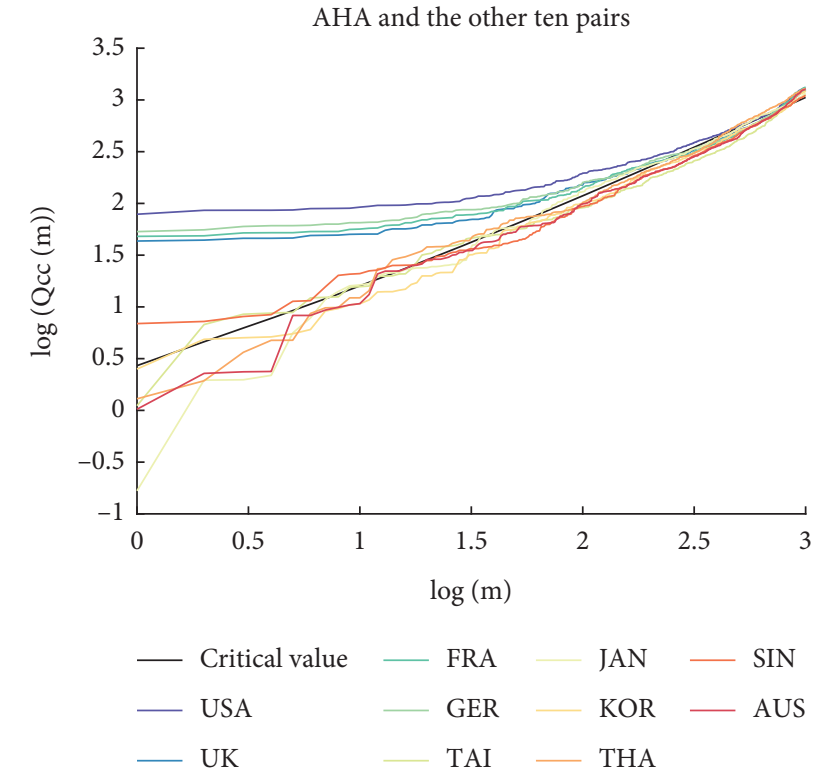

(a)

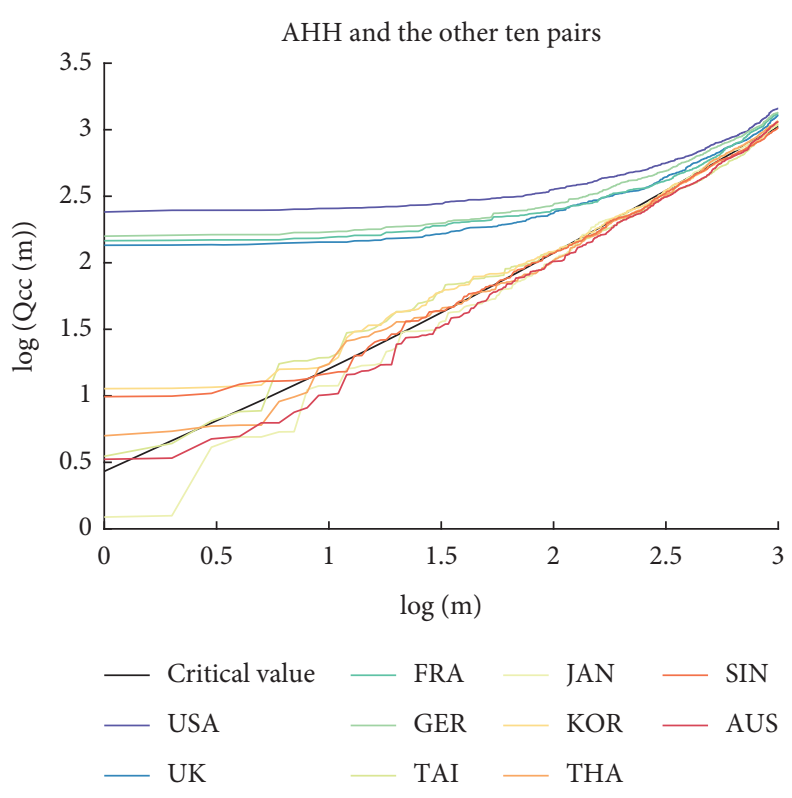

(b)

FIGURE 1: The cross-correlation statistic between AHA, AHH, and the other ten indices prices returns series (e.g., USA, UK, FRA, and GER) for the overall period with the degree of freedom varying from 1 to 1000 . Note: this figure shows the cross-correlation statistic; in each subplot, the left one shows the statistic result of AHA with the other ten pairs and the right one exhibits the AHH's. The black line corresponds to the critical value (at $10 \%$ significance level).

$\mathrm{AHH}$, and the global stock market are showing a consistent trend increasingly. Compared to the matric in the subplot (a), the greater values of the correlation coefficients in AHA imply that the multifractal cross-correlation between AHA and the other ten stock markets strengthened obviously in the postperiod. And same to the results of the preperiod, TAI, KOR, and SIN possess the top three strongest correlations with the two indices among the selected countries and the least one in AUS. The stronger interdependence between AHA, AHH, and other stock markets exists in the long-term scales than the short-term scales.

4.2. Analysis Results of MF-DCCA. In this section, we employ the tool of MF-DCCA to explore the role of the foreign investors in the cross-correlation between different stock markets. And the whole sample is divided into two subsamples of the preperiod and the postperiod for a better comparative analysis. As for the parameters need to be identified in the methodology, we follow Zhang et al. [57] to set the fitting polynomial order $k$ equals 1 , with the purpose of avoiding overfitting, and the time scale $s$ in the range of 10 to $N / 4$. ( $N$ refers to the length of the sample)

4.2.1. Preperiod Analysis. Figure 3 shows MF-DCCA analysis of AHA and AHH with the other ten pairs in the preperiod; the subplots (a), (b), and (c) exhibit the generalized Hurst exponent $H(q)$, multifractal exponent $t(q)$, and singularity spectrums using the tool of MF-DCCA, 

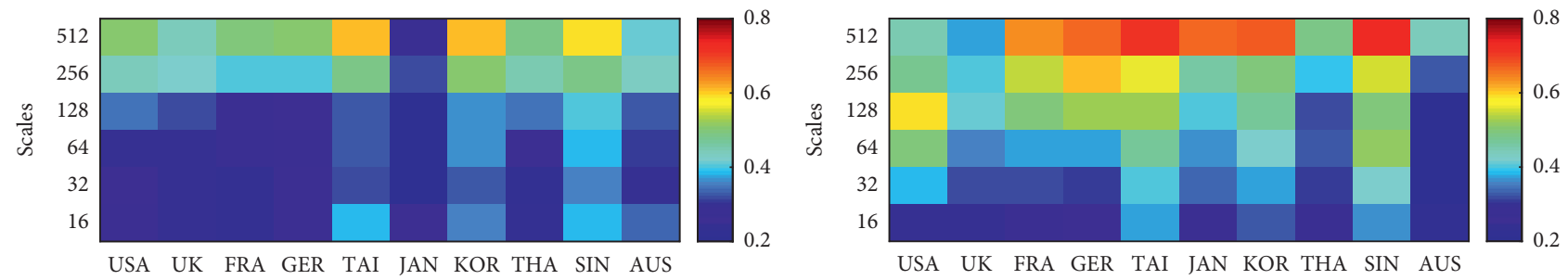

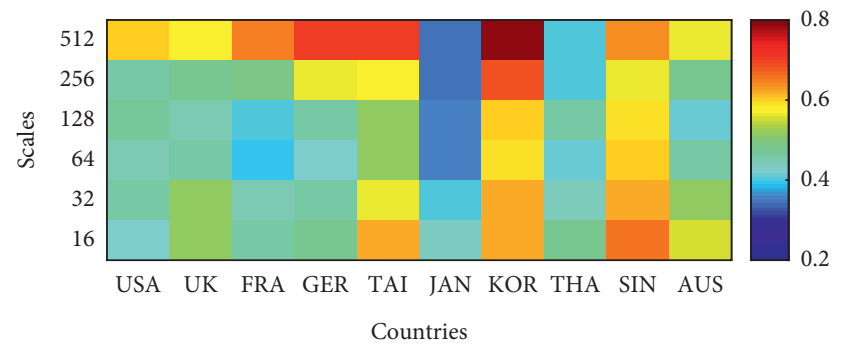

(a)

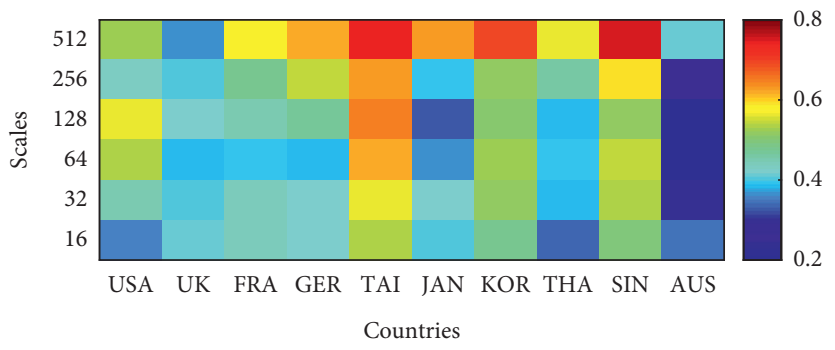

(b)

Figure 2: Cross-correlation coefficients matrix between AHA, AHH, and other ten stock indices pairs for the preperiod (a) and the postperiod (b). Note: this figure shows the variations of multifractal cross-correlation exponents; in each subplot, the higher one shows the coefficients of AHA with the other ten pairs and the lower one exhibits the AHH's. We quantify the $\rho_{\text {DCCA }}$ for different window sizes $(s=16$, $32,64,128,256$, and 512 days).

respectively. The left plot of each subplot shows the MFDCCA analysis of AHA with the other ten pairs and the right one is AHH's.

In the subplot (a), we can see that the generalized Hurst exponent $H(q)$ is the function of $q$, and decrease with the growth of $q$ in both AHA and AHH series, which indicates the cross-correlations between $\mathrm{AHA}, \mathrm{AHH}$, and the other ten pairs, is multifractal significantly; the generalized Hurst exponent $H(q)$ in AHH's fluctuate much fiercely than in AHA's, and the values of $H(q)$ in AHH are larger than AHAs with other ten series among all the range of $q$ before the SHSCP. We find that almost all values of $H(q)$ related to both positive and negative values of $q$ of AHA with other ten markets are slightly larger than 0.5 , which denote the slightly long-range persistent of large and small fluctuations that exist between AHA and other stock markets. As for AHH, for the negative $q$, the values of $H(q)$ are larger than 0.5 , which identify that the series of AHH and other stock markets are cross-persistent, so that a positive (negative) value of return is more statistically probable to be followed with another positive (negative) value [58], while for the positive $q, H_{x y}(q)<0.5$ exist in AHH with all the other ten pairs; thus, the cross-antipersistent exist in them, which corresponds to the scaling behaviors that a positive (negative) value of return is more statistically probable to be followed with another negative (positive) value. Also, the degree of multifractality index $\Delta H q$ shown in Table 2 exhibits the stronger multifractal cross-correlations in $\mathrm{AHH}$ with other markets for the preperiod, which means compared to AHA, AHH shares the much stronger comovements of the stock fluctuations with other ten pairs together.

Then, the multifractal exponent $t(q)$ of AHH in the subplot (b) (the right one) exhibits the more pronounced bending than AHA, which confirm that the much stronger multifractal cross-correlations with the other ten stock markets are in AHH than AHA. The convex parabolic shapes of the singularity spectra in the subplot (c) identify the multifractal cross-correlation in both two indices series and the width of singularity spectrums, which serves as the index of identifying the multifractal strength; we find that the width of spectrums for $\mathrm{AHH}$ with other ten pairs are much larger than AHA's on the left, showing the much stronger multifractal cross-correlations in the accessible stock market. That is, to say, the multifractal strength in cross-correlations of AHA with ten pairs is much smaller than AHH's, which may be attributed to the scarcity of the transaction of foreign investors.

4.2.2. Postperiod Analysis. The MF-DCCA analysis after the Shanghai and Hong Kong Stock Connect Program on 17 November 2014 is presented in Figure 4. The subplots (a), (b), and (c) exhibit the analysis results of generalized Hurst exponent $H(q)$, multifractal exponent $t(q)$, and singularity spectrums utilizing the tool of MF-DCCA, respectively, and for each subplot, the left plot shows the result of the AHA and the right one is AHH's.

We can see that the generalized Hurst exponent $H(q)$ in the subplot (a) is the function of $q$ and fluctuates with the change of $q$, which indicates the multifractal cross-correlations between $\mathrm{AHA}, \mathrm{AHH}$, and the other ten pairs after the SHSCP, and the contrast difference of the fluctuation between them in the preperiod even cannot be seen after reducing the regulation of the investment barriers for foreign investors in the AHA market, thus they share the much similar fluctuation of $H(q)$, and the values of $\Delta H q$ in Table 2 can also identify this result. We find the value of $H(q)$ is larger than 0.5 for the negative $q$, and the value of $H(q)$ is smaller than 0.5 for positive $q$ for AHA with other ten stock markets in the postperiod; the above results provide the 

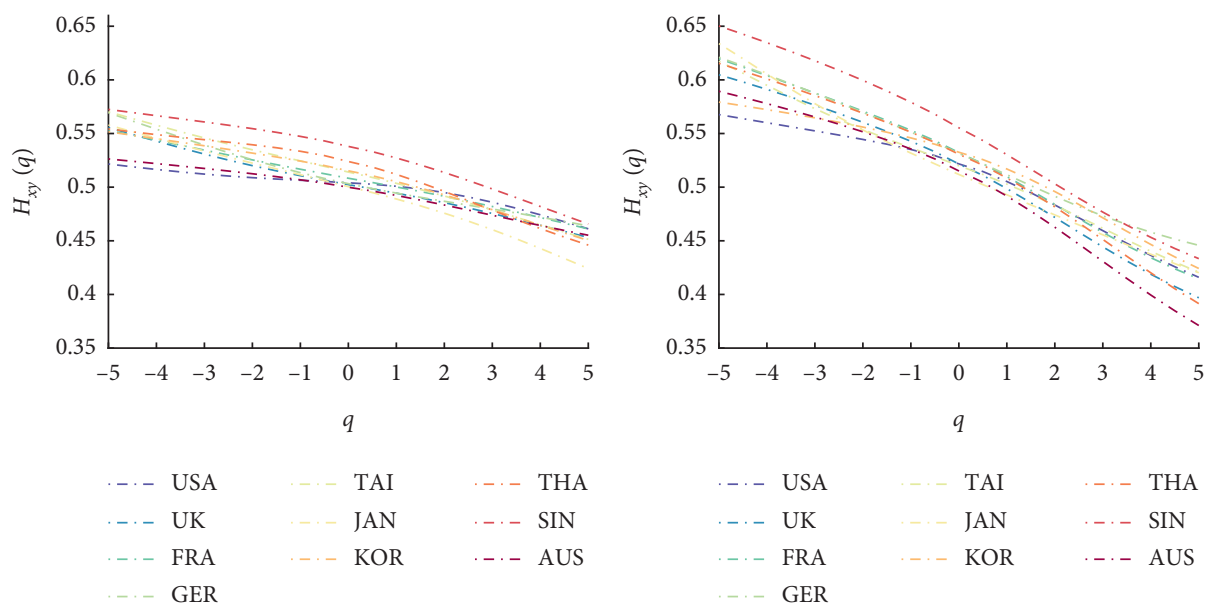

(a)
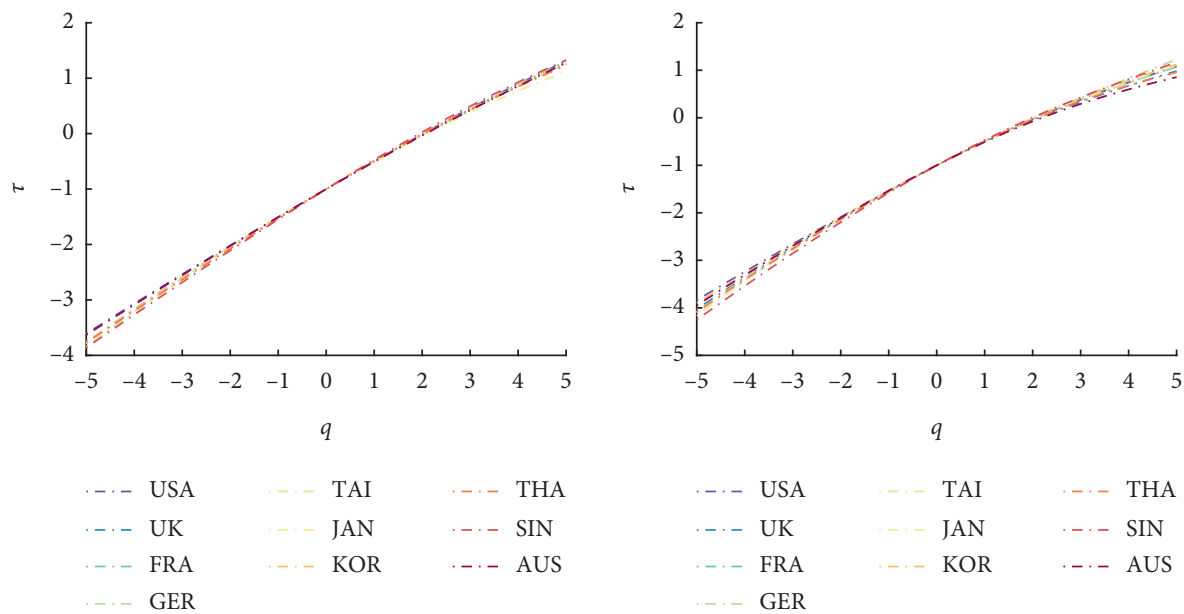

(b)
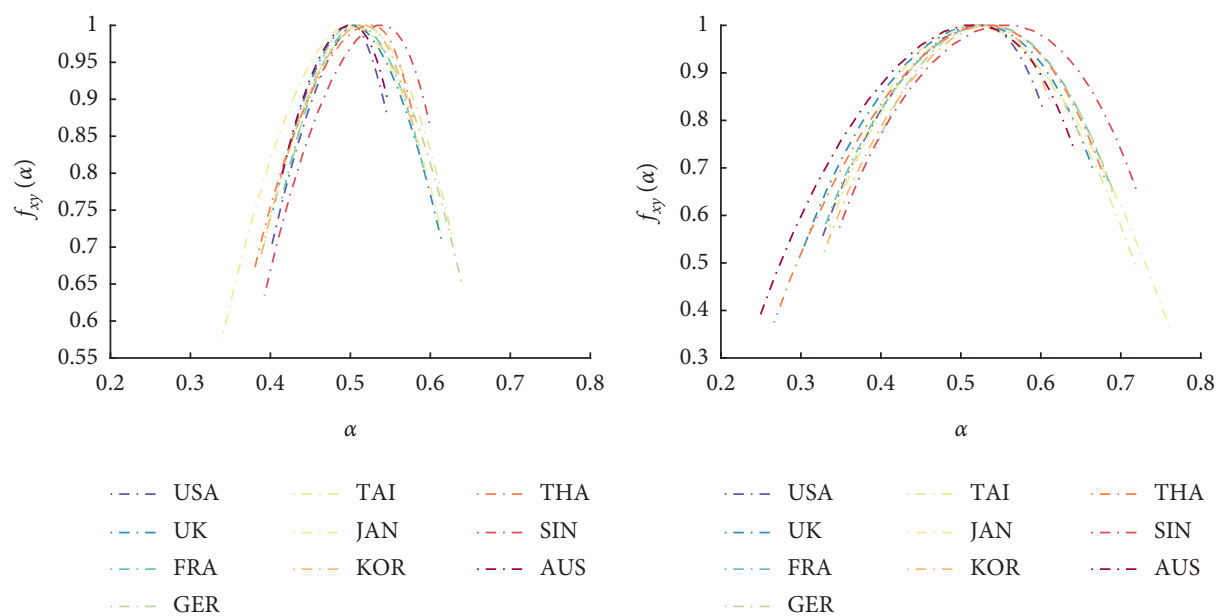

(c)

Figure 3: MF-DCCA analysis of AHA, AHH, and the other ten pairs for the preperiod. (a) Generalized Hurst exponent as a function of ( $q$ ). (b) Multifractal exponent as a function of $(q)$. (c) Singularity spectrums.

evidence that AHA's lager fluctuations with other ten pairs are persistent, while the small fluctuations are antipersistent with them, which confirm that after the openness reform of SHSCP, the interdependence between AHA and the other ten markets have been transferred from the slightly correlations to two-way fluctuation relationship.

Moreover, the bending curve of exponent $t(q)$ can be seen in the subplot (b), and there is even no difference 
TABLe 2: Multifractal degree $\Delta H q$ based on the MF-DCCA.

\begin{tabular}{lcccccccrrr}
\hline$\Delta H q$ & USA & UK & FRA & GER & TAI & JAN & KOR & THA & SIN & AUS \\
\hline Preperiod & & & & & & & & & & \\
$\Delta H(q) \_$AHA & 0.0604 & 0.1024 & 0.0918 & 0.1054 & 0.1188 & 0.1337 & 0.1013 & 0.1083 & 0.1068 & 0.0711 \\
$\Delta H(q) \_$AHH & 0.1517 & 0.2018 & 0.2051 & 0.1753 & 0.1966 & 0.2136 & 0.1551 & 0.2240 & 0.2169 & 0.2183 \\
\hline Postperiod & & & & & & & & & & \\
$\Delta H(q) \_$AHA & 0.2124 & 0.2153 & 0.1460 & 0.1189 & 0.1356 & 0.2197 & 0.1304 & 0.2077 & 0.1133 & 0.0850 \\
$\Delta H(q) \_$AHH & 0.1862 & 0.1251 & 0.1016 & 0.1181 & 0.1538 & 0.1253 & 0.1873 & 0.1221 & 0.0821 & 0.0573 \\
\hline
\end{tabular}

between the curvature of the lines in AHA and AHH, which identifies the fact that with the end of the segment stock market of the A-share and $\mathrm{H}$-share markets, the inaccessible stock market (AHA) strengthen the multifractal crosscorrelations with the global stock market significantly. As for the singularity spectrums in the subplot (c), we can still find the shape of convex parabolic in it, which confirms the multifractal cross-correlation between AHA and AHH with the other markets, while the transactions of foreign investors may benefit in reducing the divergence between the multifractal correlations of AHA and AHH with the world after the SHSCP.

From the analysis based on the tool of multifractal, we provide the evidence that the role of foreign investors may strengthen the multifractal cross-correlations of the stock markets. Moreover, the further detailed analysis, even the directional spillovers of each country, is discussed in the following.

4.3. Results of D.Y. Spillover Index. As for the question mentioned in the study by Zhou [59], finite size effects in time series may cause the strong multifractal of time series and are amplified additionally by memory effects in series [58], which may have an effect on the credibility of our research to reach a conclusion of the effect of foreign investors on the cross-correlations between different stock markets. Thus, to further discuss and verify the effect that the foreign investor have on the correlations (interdependence) between stock markets, we employ the tool of Diebold-Yilmaz spillover index to investigate the particular relations between each market. Moreover, to enhance rigorous of our result, we follow Diebold and Yilmaz to utilize the data of weekly frequency in our study, and the empirical analysis of D.Y. spillover index for the two subperiods are showing as follows.

Table 3 shows the return fluctuation spillover structure of AHA, AHA, and the other ten pairs in the preperiod when the A-share and H-share markets are still in the stage of the segmentation, and the spillover indices are calculated based on VAR of order 1 and a 2-week ahead forecast error decomposition, which is based on the Akaike information criterion (AIC). The numerical values of the diagonal part are marked in blue, which is more significant than other pairwise representing the part of the country's stock market fluctuations explained by themselves, the values in each column and row stand for spillover index received from other markets and spillover index given to others, a total of which exhibited in Table 3 named "FROM," “TO," and "NET" is the difference between them.

We can see the "Total" equals $75.89 \%$, which means that more than three-quarters of the forecast error variance in the whole sample comes from spillovers and less than onequarter correlation is determined by the internal factors. Moreover, spillover index of $\mathrm{AHH}$ is larger than AHA in terms of "FROM," "TO," and "NET." As shown in Table 3, the value of AHA receiving and transmitting the total spillover from/to other market is $60.16 \%$ and $31.11 \%$, respectively, less than the values of $76.53 \%$ and $74.50 \%$ of AHH. To maintain the comparability of empirical results with the symmetric measure of multifractality above, we set the parameter "Total Correlation" as the sum of "TO" and "FROM," which corresponds to the total correlation with the whole stock markets except the market itself. We can calculate the "Total Correlation" of AHA and AHH as $91.27 \%$ $(31.11 \%+60.16 \%)$ and $151.03 \%(74.50 \%+76.53 \%)$, respectively, for the preperiod, from which we can conclude that the correlation with the global stock market is much stronger in $\mathrm{AHH}$ than AHA.

Apart from total spillover index of AHA and $\mathrm{AHH}$ with the global stock market, we can also find the details of the spillovers between $\mathrm{AHH}, \mathrm{AHH}$, and other markets individually in Table 3, from which we see the larger spillovers from/to each market existing in $\mathrm{AHH}$ than AHA, which provides evidence that the $\mathrm{H}$-share market is more sensitive to the fluctuation of other stock markets than the A-share due to the participation of foreign investors. Though the evident divergence exists in $\mathrm{AHA}$ and $\mathrm{AHH}$, some common points are also found that the top three largest spillovers with AHA and AHH are TAI, KOR, and SIN, the same with the results of multifractal analysis above. Moreover, another interesting finding is the "NET" element; positive values are observed only for the developed stock market, such as AME, ENG, FRA, and GER, confirming that they are the NET transmitters of spillover to other markets.

Table 4 shows the return fluctuation spillover structure of AHA, AHA, and the other ten pairs after the end of segment stock markets of the A-share and $\mathrm{H}$-share, and the spillover indices are calculated based on VAR of order 1 and a 2 -week ahead forecast error decomposition, which is based on the Akaike information criterion (AIC). In the stage of integration stock market of the A-share and $\mathrm{H}$-share, the total spillover $77.28 \%$ is also larger than three-quarters, implying that the spillover explains most of the fluctuations for the whole sample.

Since the difference of whether shares are open to foreign investors between $\mathrm{AHA}$ and $\mathrm{AHH}$ disappeared after the 

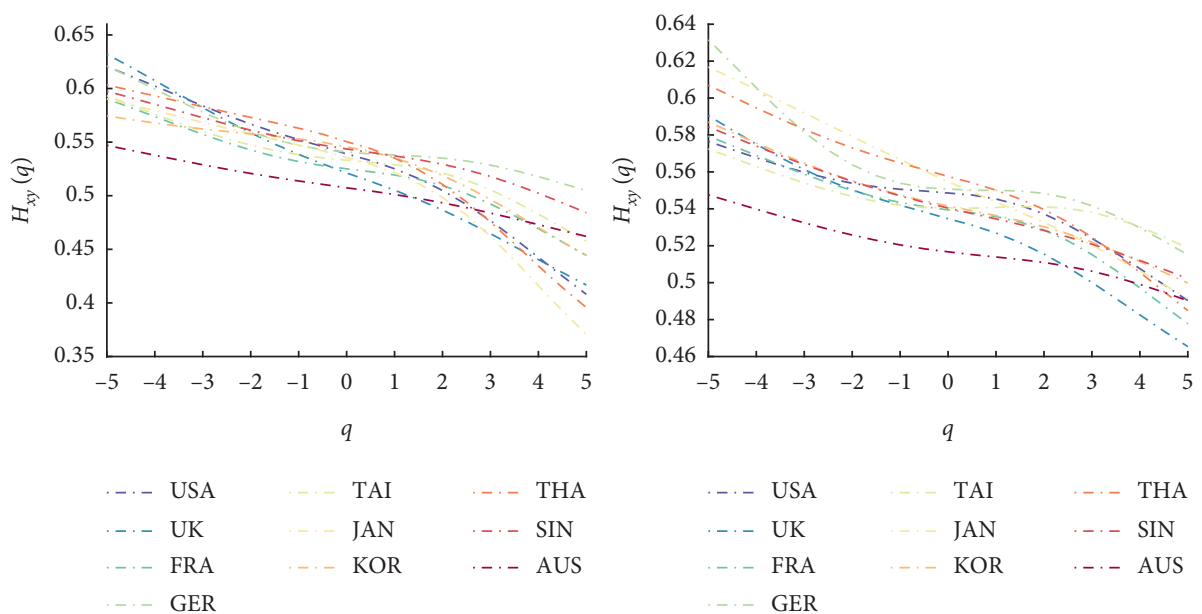

(a)
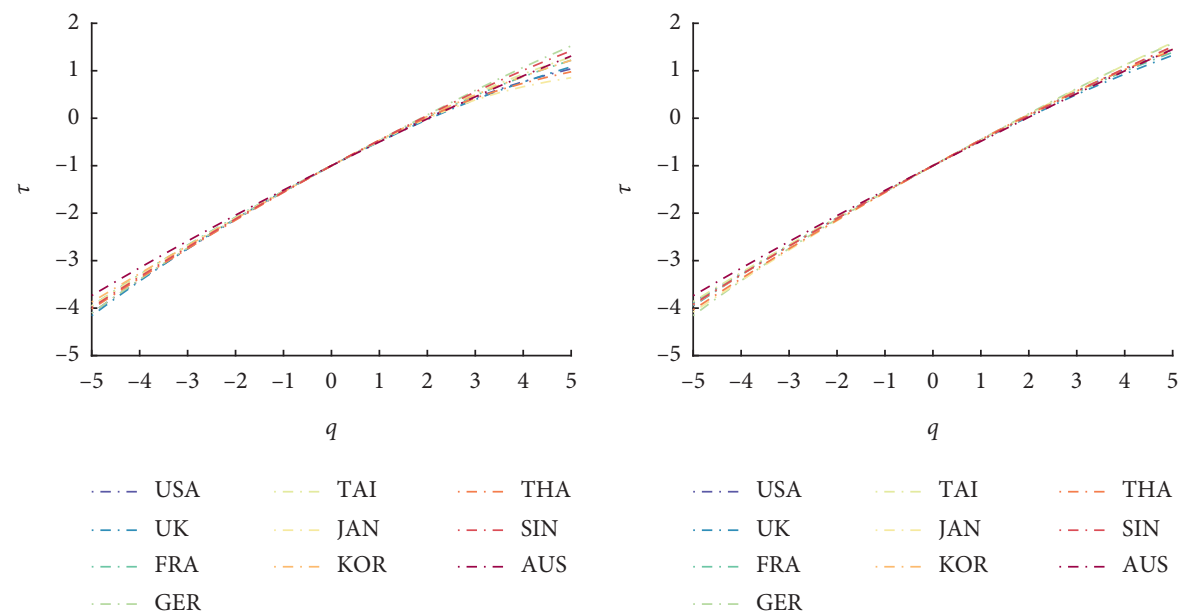

(b)
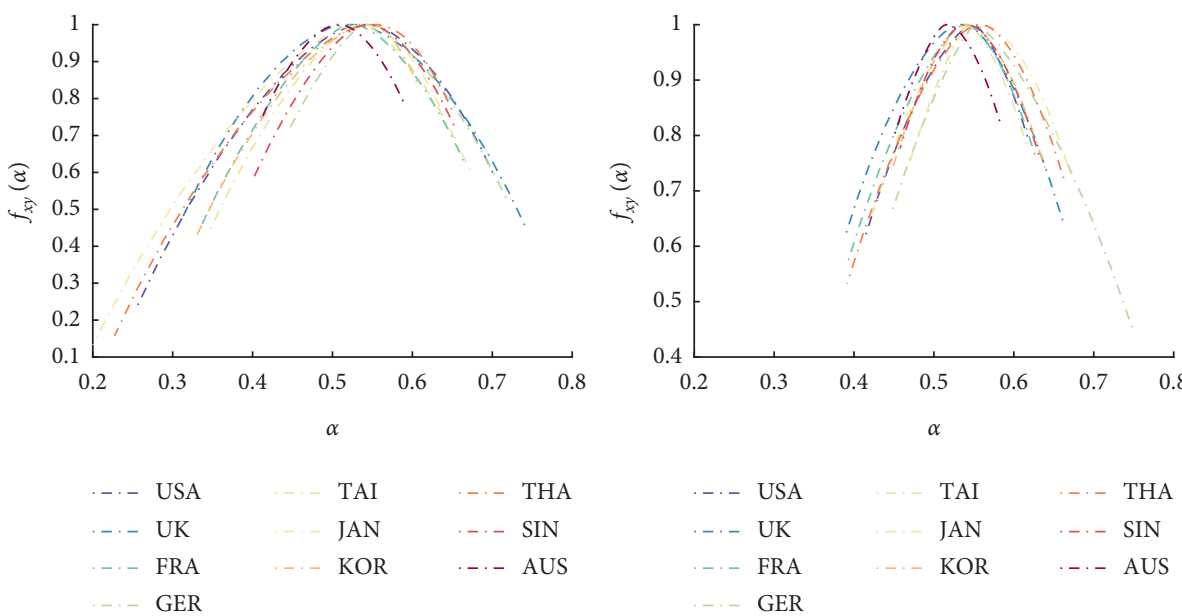

(c)

FIGURE 4: MF-DCCA analysis of AHA, AHH, and the other ten pairs for the postperiod. (a) Generalized Hurst exponent as a function of $q$. (b) Multifractal exponent as a function of $q$. (c) Singularity spectrums.

conduct of the Shanghai and Hong Kong Connect Program, the two markets sharing the same openness and without any restrictions for foreign investors to step into, we can see that the from/to spillovers of AHA increased compared to the preperiod from $60.16 \%$ and $31.11 \%$ to $65.53 \%$ and $45.60 \%$ evidently, and the "Total Correlation" of AHA and AHH for 
TABle 3: Preperiod sample return spillover table.

\begin{tabular}{lccccccccccccc}
\hline & AHA & AHH & USA & UK & FRA & GER & TAI & JAN & KOR & THA & SIN & AUS & FROM \\
\hline AHA & 39.84 & 17.96 & 4.01 & 4.87 & 3.41 & 3.07 & 5.11 & 2.36 & 5.35 & 2.38 & 6.56 & 5.08 & 60.16 \\
AHH & 10.64 & 23.47 & 5.54 & 6.38 & 5.50 & 5.65 & 7.35 & 5.53 & 8.55 & 5.04 & 9.73 & 6.63 & 76.53 \\
USA & 1.69 & 4.11 & 17.97 & 13.47 & 13.14 & 12.60 & 6.05 & 6.01 & 6.60 & 2.73 & 6.61 & 9.01 & 82.03 \\
UK & 1.93 & 4.33 & 12.64 & 16.80 & 13.19 & 12.50 & 6.28 & 5.81 & 6.73 & 2.39 & 7.31 & 10.08 & 83.20 \\
FRA & 1.35 & 3.98 & 12.78 & 13.67 & 17.34 & 14.51 & 6.16 & 5.84 & 6.87 & 2.17 & 6.62 & 8.69 & 82.66 \\
GER & 1.19 & 4.20 & 12.56 & 13.25 & 14.94 & 18.00 & 6.06 & 5.68 & 7.07 & 2.23 & 6.88 & 7.94 & 82.00 \\
TAI & 2.66 & 6.40 & 7.24 & 7.94 & 7.38 & 7.04 & 21.25 & 5.90 & 11.99 & 3.92 & 9.77 & 8.50 & 78.75 \\
JAN & 1.47 & 5.82 & 8.55 & 8.75 & 8.46 & 7.97 & 6.88 & 24.96 & 6.82 & 2.54 & 9.52 & 8.27 & 75.04 \\
KOR & 2.64 & 7.17 & 7.32 & 7.95 & 7.83 & 7.76 & 11.30 & 5.44 & 19.72 & 4.41 & 10.13 & 8.32 & 80.28 \\
THA & 2.22 & 7.60 & 5.61 & 5.54 & 4.51 & 4.38 & 6.54 & 3.75 & 7.92 & 35.49 & 11.33 & 5.10 & 64.51 \\
SIN & 3.00 & 7.62 & 7.35 & 8.49 & 7.39 & 7.29 & 8.56 & 7.11 & 9.71 & 5.81 & 18.78 & 8.88 & 81.22 \\
AUS & 2.29 & 5.29 & 9.64 & 11.45 & 9.58 & 8.59 & 8.11 & 6.31 & 8.24 & 2.53 & 8.90 & 19.05 & 80.95 \\
\hline TO & 31.11 & 74.50 & 93.23 & 101.77 & 95.34 & 91.37 & 78.40 & 59.73 & 85.85 & 36.16 & 93.36 & 86.52 & Total=75.89 \\
NET & -29.05 & -2.03 & 11.20 & 18.57 & 12.68 & 9.37 & -0.35 & -15.31 & 5.57 & -28.35 & 12.14 & 5.57 & \\
\hline
\end{tabular}

Note. The upper-left $12 \times 12$ market submatrix gives the $i j^{\text {th }}$ pairwise directional spillover index. The "FROM" column gives total directional connectedness of from, which is the row sums. The "TO" row gives total directional connectedness of to, which is the column sums. The "NET" row measures the difference in total directional connectedness (TO-FROM). The bottom-right element "Total" is the mean of "FROM," or equivalently, mean of "TO," which mirrors the total connectedness.

TABLE 4: Postperiod sample return spillover table.

\begin{tabular}{lccccccccccccc}
\hline & AHA & AHH & USA & UK & FRA & GER & TAI & JAN & KOR & THA & SIN & AUS & FROM \\
\hline AHA & 34.67 & 23.22 & 4.83 & 3.15 & 4.91 & 5.04 & 5.49 & 3.37 & 4.39 & 3.29 & 6.80 & 0.83 & 65.33 \\
AHH & 18.77 & 27.95 & 4.91 & 3.46 & 5.19 & 5.51 & 8.81 & 4.44 & 6.59 & 3.50 & 8.99 & 1.88 & 72.05 \\
USA & 2.68 & 3.35 & 21.28 & 10.17 & 10.53 & 9.58 & 6.98 & 8.76 & 7.64 & 4.38 & 7.47 & 7.18 & 78.72 \\
UK & 2.18 & 2.85 & 10.43 & 21.17 & 13.17 & 11.06 & 5.88 & 7.13 & 7.15 & 4.59 & 7.05 & 7.34 & 78.83 \\
FRA & 2.81 & 3.61 & 8.99 & 11.20 & 17.99 & 15.46 & 5.71 & 9.87 & 7.23 & 4.75 & 6.80 & 5.58 & 82.01 \\
GER & 2.93 & 4.05 & 8.78 & 10.07 & 16.47 & 19.09 & 5.58 & 9.83 & 6.81 & 4.29 & 6.50 & 5.61 & 80.91 \\
TAI & 3.61 & 7.22 & 7.53 & 6.22 & 7.18 & 6.66 & 23.01 & 6.42 & 11.99 & 5.50 & 9.29 & 5.37 & 76.99 \\
JAN & 2.14 & 3.49 & 8.96 & 6.94 & 12.03 & 11.29 & 5.98 & 21.73 & 8.76 & 3.60 & 8.32 & 6.76 & 78.27 \\
KOR & 2.56 & 5.06 & 7.72 & 7.16 & 8.78 & 7.87 & 11.31 & 8.74 & 21.66 & 4.86 & 8.92 & 5.35 & 78.34 \\
THA & 2.95 & 3.72 & 6.71 & 6.98 & 8.48 & 7.22 & 7.34 & 5.41 & 6.74 & 31.75 & 7.47 & 5.22 & 68.25 \\
SIN & 4.13 & 6.83 & 8.10 & 7.82 & 8.68 & 7.63 & 8.50 & 7.90 & 8.58 & 4.96 & 20.92 & 5.95 & 79.08 \\
AUS & 0.85 & 1.97 & 9.27 & 9.35 & 8.59 & 8.09 & 6.34 & 8.54 & 6.61 & 4.45 & 7.90 & 28.04 & 71.96 \\
\hline TO & 45.60 & 65.37 & 86.23 & 82.52 & 104.01 & 95.42 & 77.92 & 80.41 & 82.50 & 48.17 & 85.51 & 57.08 & \multirow{2}{*}{ Total=77.28 } \\
NET & -19.73 & -6.68 & 7.51 & 3.69 & 22.00 & 14.51 & 0.93 & 2.14 & 4.16 & -20.08 & 6.43 & -14.88 & \\
\hline
\end{tabular}

Note. The underlying variance decomposition is based upon VAR of order 1 , and the predictive horizon is 2 . The upper-left $12 \times 12$ market submatrix gives the $i j^{\text {th }}$ pairwise directional spillover index. The "FROM" column gives total directional connectedness of from, which is the row sums. The "TO" row gives total directional connectedness of to, which is the column sums. The "NET" row measures the difference in total directional connectedness (TO-FROM). The bottom-right element "Total" is the mean of "FROM," or equivalently, mean of "TO," which mirrors the total connectedness.

the postperiod is $110.93 \%(45.60 \%+65.33 \%)$ and $137.42 \%$ $(65.37 \%+72.05 \%)$, respectively, which identifies the narrowed difference in correlations between $\mathrm{AHA}, \mathrm{AHH}$, and the global stock market. As for the from/to spillover for AHA and AHH with each market, we can also find the three largest values that exist in TAI, KOR, and SIN, which possess the strongest correlations with AHA and $\mathrm{AHH}$, besides the weakest correlation in AUS. The same results as the preperiod; the positive net spillovers are still for developed stock markets such as AME, ENG, and GER. Though AHA is still a receiver of spillover in the postperiod, the net spillover already increased from $-29.05 \%$ to $-19.73 \%$, which means the impact of the stock market in the mainland China on the global markets is growing gradually with the deregulation of the capital market step by step. While it is still greatly affected by the international stock market, thus, more regulation reforms need to be conducted gradually to open
China's stock market to foreign investors and enhance the influence of China's capital market.

The analysis in this section shows that much larger spillovers can be found in AHH than AHA in the preperiod. While after the liberation of the inaccessible stock market, the spillovers of AHA with the global stock markets strengthened significantly compared to the preperiod. Both the comparison of AHA and $\mathrm{AHH}$ in the preperiod and the contrast of AHA in the two subperiods all confirm the effect that the foreign investors have on the correlation of stock markets.

\section{Robustness Test}

Apart from the significant divergence of degree of openness between accessible and inaccessible stock markets, there are also several differences that exist in the shares cross-listed in 
TABLE 5: Return spillover table of SHCI with other stock markets in the preperiod.

\begin{tabular}{lccccccccccccc}
\hline & SHCI & AHH & USA & UK & FRA & GER & TAI & JAN & KOR & THA & SIN & AUS & FROM \\
\hline SHCI & 43.64 & 15.68 & 3.91 & 4.90 & 3.44 & 2.58 & 4.67 & 2.74 & 5.63 & 2.37 & 5.02 & 5.43 & 56.36 \\
AHH & 8.69 & 24.06 & 5.62 & 6.50 & 5.62 & 5.77 & 7.52 & 5.61 & 8.73 & 5.17 & 9.93 & 6.77 & 75.94 \\
USA & 1.53 & 4.09 & 18.02 & 13.50 & 13.18 & 12.63 & 6.09 & 6.01 & 6.61 & 2.71 & 6.62 & 9.02 & 81.98 \\
UK & 1.83 & 4.32 & 12.66 & 16.84 & 13.20 & 12.51 & 6.34 & 5.80 & 6.73 & 2.36 & 7.32 & 10.09 & 83.16 \\
FRA & 1.27 & 3.98 & 12.80 & 13.68 & 17.37 & 14.52 & 6.24 & 5.82 & 6.87 & 2.14 & 6.63 & 8.69 & 82.63 \\
GER & 0.99 & 4.20 & 12.59 & 13.28 & 14.97 & 18.06 & 6.12 & 5.67 & 7.08 & 2.20 & 6.89 & 7.95 & 81.94 \\
TAI & 2.25 & 6.40 & 7.27 & 8.00 & 7.47 & 7.10 & 21.26 & 5.92 & 12.03 & 3.96 & 9.80 & 8.55 & 78.74 \\
JAN & 1.59 & 5.77 & 8.55 & 8.74 & 8.43 & 7.94 & 6.91 & 24.99 & 6.81 & 2.50 & 9.52 & 8.25 & 75.01 \\
KOR & 2.56 & 7.16 & 7.32 & 7.95 & 7.84 & 7.76 & 11.35 & 5.44 & 19.76 & 4.40 & 10.14 & 8.32 & 80.24 \\
THA & 1.91 & 7.66 & 5.60 & 5.52 & 4.48 & 4.35 & 6.64 & 3.72 & 7.93 & 35.72 & 11.38 & 5.10 & 64.28 \\
SIN & 2.21 & 7.66 & 7.40 & 8.56 & 7.46 & 7.35 & 8.66 & 7.16 & 9.79 & 5.85 & 18.95 & 8.95 & 81.05 \\
AUS & 2.30 & 5.28 & 9.63 & 11.45 & 9.58 & 8.58 & 8.16 & 6.30 & 8.24 & 2.51 & 8.90 & 19.07 & 80.93 \\
\hline TO & 27.13 & 72.19 & 93.35 & 102.08 & 95.66 & 91.10 & 78.71 & 60.18 & 86.44 & 36.16 & 92.14 & 87.12 & \multirow{2}{*}{ Total= $=76.86$} \\
NET & -29.23 & -3.75 & 11.37 & 18.92 & 13.03 & 9.15 & -0.03 & -14.83 & 6.20 & -28.12 & 11.09 & 6.19 \\
\hline
\end{tabular}

Note. The underlying variance decomposition is based upon a VAR of order 1 , and the predictive horizon is 2 . The upper-left $12 \times 12$ market submatrix gives the $i j^{\text {th }}$ pairwise directional spillover index. The "FROM" column gives total directional connectedness of from, which is the row sums. The "TO" row gives total directional connectedness of to, which is the column sums. The "NET" row measures the difference in total directional connectedness (TO-FROM). The bottom-right element "Total" is the mean of "FROM," or equivalently, mean of "TO," which mirrors the total connectedness.

both A-share and $\mathrm{H}$-share markets in China, such as the rules of transaction, limits on fluctuations, and so on, which may influence the different behaviors in the stock market of $\mathrm{AHA}$ and $\mathrm{AHH}$. Thus, to enhance the credibility of our research, we follow the method of $\mathrm{Li}$ et al. [26] to employ Shanghai Composite Index (SHCI) of Shanghai Stock Exchange in mainland China to serve as the proxy of inaccessible stocks after the openness reform of SHSCP because it is an extremely difficult and complex work to compile the inaccessible stock index with those shares inaccessible to foreign investors after the openness reform.

It seems problematic to make the SHCI as the proxy index of inaccessible stocks due to the fact that there are about half of the shares included in SHCI that became accessible after the reform. As the AHA and SHCI expose to the same trading system and are restricted to the same regulations of transaction in Mainland China, taking SHCI as the proxy may underestimate the effect of openness because it is not the index that cannot be traded by foreign investors at all after SHSCP but with half of newly accessible shares to foreigners. While if the empirical results exhibit that the values of spillover index of SHCI are smaller than AHA's in the postperiod slightly, we can conclude that the foreign investors indeed strengthen the correlations between different stock markets confidently. Therefore, the use of SHCI as such a proxy of the inaccessible market for the postperiod is reasonable and feasible.

The return fluctuation spillover matrix of SHCI, AHA, and the other ten pairs in the preperiod when the A-share and $\mathrm{H}$-share markets are still in the stage of the segmentation is shown in Table 5, and the spillover indices are calculated based on VAR of order 1 and a 2-week ahead forecast error decomposition, which is based on the Akaike information criterion (AIC).

We suppose that the values of their spillover index will be similar because both the SHCI and AHA are all inaccessible to foreign investors before the openness reform of SHSCP. Thus, the D.Y. spillover index tool is utilized again to identify our hypothesis. And the empirical results are shown in Table 5. SHCI receives and transmits the total spillover from and to other markets at $56.36 \%$ and $27.13 \%$, which is similar to the spillover indices of AHA shown in Table 3, 60.16\% and $31.11 \%$, respectively. As for each spillover index between SHCI, AHA, and other markets individually, we can find that there is almost no difference between the values of indices of SHCI and AHA with other market pairs. The calculated values of the "Total Correlation" of SHCI and AHA in the preperiod is $83.49 \%$ and $91.27 \%$, respectively, in which there is no evident difference between them because the two indices of SHCI and AHA are all inaccessible to foreign investors, and they expose to the same regulations of transaction in Mainland China before the openness reform of SHSCP. Thus, the similar results of the spillover effect exist in SHCI and AHA, which just confirm our hypothesis mentioned above. And we also find that similar to AHA, SHCI is also affected strongly by other stock markets, while it is not responsive to the stock return fluctuations of other pairs.

Table 6 shows the return fluctuation spillover structure of SHCI, AHH, and the other ten pairs after the end of segment stock markets of the A-share and $\mathrm{H}$-share, and the spillover indices are calculated based on VAR of order 1 and a 2-week ahead forecast error decomposition, which is based on the Akaike information criterion (AIC).

From Table 6, we can find that the total TO and FROM spillover index of SHCI have a small increase from $27.13 \%$ to $36.20 \%$ and from $56.36 \%$ to $59.67 \%$; compared with results of AHA shown in Table 4, the spillover ones increase from $31.11 \%$ to $45.60 \%$ and from $60.16 \%$ to $65.53 \%$ evidently, and the larger difference of spillover index at the two stages of before and after the Shanghai-Hong Kong Stock Connect Program exists in AHA. Because AHA is transferred to be accessible to foreign investors after the reform, the larger spillovers can be seen in it, while, as for SHCI, serving as the proxy of inaccessible to foreign investors after the openness reform, also strengthen the correlation with other stock 
TABLE 6: Return spillover table of SHCI with other stock markets in the postperiod.

\begin{tabular}{lccccccccccccc}
\hline & SHCI & AHH & USA & UK & FRA & GER & TAI & JAN & KOR & THA & SIN & AUS & FROM \\
\hline SHCI & 40.33 & 17.28 & 5.64 & 3.80 & 5.12 & 5.26 & 4.65 & 3.65 & 3.99 & 2.54 & 7.08 & 0.67 & 59.67 \\
AHH & 13.17 & 30.16 & 5.17 & 3.66 & 5.50 & 5.90 & 9.41 & 4.70 & 6.91 & 3.78 & 9.65 & 1.98 & 69.84 \\
USA & 2.63 & 3.23 & 21.21 & 10.17 & 10.52 & 9.51 & 6.98 & 8.74 & 7.80 & 4.57 & 7.49 & 7.15 & 78.79 \\
UK & 1.91 & 2.79 & 10.45 & 21.16 & 13.18 & 11.04 & 5.90 & 7.13 & 7.25 & 4.76 & 7.10 & 7.34 & 78.84 \\
FRA & 2.29 & 3.55 & 9.04 & 11.24 & 18.03 & 15.47 & 5.74 & 9.89 & 7.35 & 4.95 & 6.88 & 5.59 & 81.97 \\
GER & 2.42 & 4.02 & 8.77 & 10.10 & 16.51 & 19.17 & 5.61 & 9.84 & 6.87 & 4.47 & 6.59 & 5.62 & 80.83 \\
TAI & 2.73 & 7.20 & 7.61 & 6.29 & 7.27 & 6.73 & 23.16 & 6.49 & 12.07 & 5.65 & 9.39 & 5.41 & 76.84 \\
JAN & 2.34 & 3.40 & 8.92 & 6.91 & 11.96 & 11.18 & 5.97 & 21.58 & 8.84 & 3.80 & 8.37 & 6.71 & 78.42 \\
KOR & 2.10 & 4.90 & 7.90 & 7.25 & 8.89 & 7.90 & 11.30 & 8.87 & 21.63 & 4.98 & 8.91 & 5.38 & 78.37 \\
THA & 1.98 & 3.67 & 6.95 & 7.16 & 8.71 & 7.40 & 7.44 & 5.65 & 6.87 & 31.37 & 7.48 & 5.32 & 68.63 \\
SIN & 3.79 & 6.78 & 8.15 & 7.87 & 8.74 & 7.68 & 8.53 & 8.00 & 8.57 & 5.01 & 20.90 & 5.99 & 79.10 \\
AUS & 0.84 & 1.93 & 9.24 & 9.33 & 8.57 & 8.06 & 6.34 & 8.51 & 6.66 & 4.59 & 7.94 & 27.98 & 72.02 \\
\hline TO & 36.20 & 58.76 & 87.84 & 83.79 & 104.97 & 96.11 & 77.88 & 81.46 & 83.17 & 49.10 & 86.88 & $57.17 \%$ & \multirow{2}{*}{ Total=75.28 } \\
NET & -23.47 & -11.08 & 9.05 & 4.95 & 23.00 & 15.28 & 1.03 & 3.04 & 4.80 & -19.53 & 7.77 & -14.85 & \\
\hline
\end{tabular}

Note. The underlying variance decomposition is based upon a VAR of order 1 , and the predictive horizon is 2 . The upper-left $12 \times 12$ market submatrix gives the $i j^{\text {th }}$ pairwise directional spillover index. The "FROM" column gives total directional connectedness of from, which is the row sums. The "TO" row gives total directional connectedness of to, which is the column sums. The "NET" row measures the difference in total directional connectedness (TO-FROM). The bottom-right element "Total" is the mean of "FROM," or equivalently, mean of "TO," which mirrors the total connectedness.

markets with a small increase, which can be explained by the fact that there are still about half of shares that are transferred to be tradable to foreign investors, so the small growth exists in it.

The empirical result derived from the comparison between AHA and AHH before and after the openness reform is not enough to reach the conclusion that foreign investors enhance the correlations between different stock markets because there are also other factors that may affect the results of our research. Thus, the index of SHCI is selected as the proxy of inaccessible stock market after the reform to investigate the effect of foreign investors in strengthening the correlations between different stock markets, which is a suitable and perfect parameter tool to support our research. And the analysis with SHCI also provides the significant evidence that after the openness reform, the inaccessible stock market was transferred to the accessible one, which relaxed the limitations of transaction to foreign investors, thus enhancing the correlation with the global stock market.

\section{Conclusion}

In this paper, we investigated the effect that the foreign investors have on the cross-correlations between different stock markets from the aspect of the segment stock market, and the methodologies of the multifractal detrended crosscorrelation analysis (MF-DCCA) and Diebold-Yilmaz spillover index we employed confirm the consistent conclusion that the foreign investors indeed enhance the crosscorrelations between different markets. The unique feature of the segment stock market of the A-share and $\mathrm{H}$-share markets makes China's stock market the suitable and perfect sample to be utilized to conduct our research.

The tool of the cross-correlation test provides the qualitative evidence that the significant cross-correlations exist in both AHA and AHH with the global stock markets for the whole sample. The results of the coefficient matrices of cross-correlation and MF-DCCA identify that the multifractal cross-correlation coefficients of $\mathrm{AHH}$ with the other ten stock markets are much larger than AHA's in the preperiod, and the strengthened interdependence between AHA and the other ten pairs can be seen after the ShanghaiHong Kong connect Program on November 17, 2014. Another new method of spillover index is borrowed from Diebold and Yilmaz to explore directional spillovers of AHA and $\mathrm{AHH}$ with global stock markets, and the conclusions derived from the D.Y. spillovers are consistent with the analysis of the multifractal tools in general. Moreover, Taiwan, Korea, and Singapore exhibit the strongest correlations with AHA and AHH among these markets for the whole sample; in contrast, the weakest correlation is in the Australia market, which may provide some advisable reference for the diversification investment of investors.

With the integration of the global stock markets, the correlations between countries are becoming stronger, and such integration progression indeed benefits the flow of the capital to find the optimal investment opportunity, while the stock markets also suffer from the intensive fluctuation at the same time. The catastrophic damages caused by the global financial crisis on the worldwide countries always remind us that it is urgent to investigate the reason that causes the strengthened interdependence between different stock markets, which may help in reducing the damage to countries' economics, and preventing such extreme events from happening again. And this paper may contribute to the studies in exploring the factors that affect the interdependence between countries from a novel point of view.

\section{Data Availability}

The data used to support the findings of this study are available from the corresponding author upon request. 


\section{Conflicts of Interest}

The authors declare that they have no conflicts of interest.

\section{Acknowledgments}

This work was supported by the National Natural Science Foundation of China (71773024), the Natural Science Foundation of Heilongjiang Province of China (G2018006), and the Heilongjiang Postdoctoral Scientific Research Developmental Fund (LBH-Q18064).

\section{References}

[1] A. S. Soofi, Z. Li, and X. F. Hui, "Nonlinear interdependence of the Chinese stock markets," Quatitative Finance, vol. 12, no. 3, pp. 135-149, 2012.

[2] H. Q. Zhu, Z. D. Lu, S. Y. Wang et al., "Causal linkages among Shanghai, Shenzhen, and Hong Kong stock markets," International Journal of Theoretical and Applied Finance, vol. 2, no. 7, pp. 135-149, 2004.

[3] S. Gulzar, G. Mujtaba Kayani, H. Ayub, and A. Rafique, "Financial cointegration and spillover effect of global financial crisis: a study of emerging Asian financial markets," Economic Research-Ekonomska Istraživanja, vol. 32, no. 1, pp. 187-218, 2019.

[4] E. Warshaw, "Asymmetric volatility spillover between European equity and foreign exchange markets: evidence from the frequency domain," International Review of Economics \& Finance, vol. 68, pp. 1-14, 2020.

[5] R. S. Pindyck and J. J. Rotemberg, "The comovement of stock prices," The Quarterly Journal of Economics, vol. 108, no. 4, pp. 1073-1104, 1993.

[6] N. G. Mankiw, "The equity premium and the concentration of aggregate shocks," Journal of Financial Economics, vol. 17, no. 1, pp. 211-219, 1986.

[7] M. A. King and S. Wadhwani, "Transmission of volatility between stock markets," Review of Financial Studies, vol. 3, no. 1, pp. 5-35, 1990.

[8] G. A. Karolyi and R. M. Stulz, "Why do markets move together? an investigation of U.S.-Japan stock return comovements," The Journal of Finance, vol. 51, no. 3, pp. 951-986, 1996.

[9] R. A. Connolly and F. A. Wang, "International equity market comovements: economic fundamentals or contagion?" $\mathrm{Pa}$ cific-Basin Finance Journal, vol. 11, no. 1, pp. 23-43, 2003.

[10] A. S. Kyle and W. Xiong, "Contagion as a wealth effect," The Journal of Finance, vol. 56, no. 4, pp. 1401-1440, 2001.

[11] M. K. Brunnermeier and L. H. Pedersen, "Market liquidity and funding liquidity," Review of Financial Studies, vol. 22, no. 6, pp. 2201-2238, 2009.

[12] K. Yuan, "Asymmetric price movements and borrowing constraints: a rational expectations equilibrium model of crises, contagion, and confusion," The Journal of Finance, vol. 60, no. 1, pp. 379-411, 2005.

[13] D. Petmezas and D. Santamaria, "Investor induced contagion during the banking and European sovereign debt crisis of 2007-2012: wealth effect or portfolio rebalancing?" Journal of International Money and Finance, vol. 49, no. B, pp. 401-424, 2014.

[14] P. Hartmann, S. Straetmans, and C. G. d. Vries, “Asset market linkages in crisis periods," Review of Economics and Statistics, vol. 86, no. 1, pp. 313-326, 2004.
[15] R. Connolly, C. Stivers, and L. Sun, "Stock market uncertainty and the stock-bond return relation," Journal of Financial and Quantitative Analysis, vol. 40, no. 1, pp. 161-194, 2005.

[16] D. Su, "Asset pricing in a segmented emerging market," Journal of Applied Economics, vol. 3, no. 2, pp. 387-412, 2000.

[17] T. C. Chiang, L. Tan, and H. Li, "Empirical analysis of dynamic correlations of stock returns: evidence from Chinese A-share and B-share markets," Quantitative Finance, vol. 7, no. 6, pp. 651-667, 2007.

[18] S. Chakravarty, A. Sarkar, and L. Wu, "Information asymmetry, market segmentation and the pricing of cross-listed shares: theory and evidence from Chinese A and B shares," Journal of International Financial Markets, Institutions and Money, vol. 8, no. 3-4, pp. 325-356, 1998.

[19] T. C. Chiang, E. Nelling, and L. Tan, "The speed of adjustment to information: evidence from the Chinese stock market," International Review of Economics \& Finance, vol. 17, no. 2, pp. 216-229, 2008.

[20] Q. Sun and W. H. S. Tong, "The effect of market segmentation on stock prices: the China syndrome," Journal of Banking \& Finance, vol. 24, no. 12, pp. 1875-1902, 2000.

[21] G. B. Kadlec and J. J. Mcconnell, "The effect of market segmentation and illiquidity on asset prices: evidence from exchange listings," The Journal of Finance, vol. 49, no. 2, pp. 611-636, 1994.

[22] Y. Shi, M. Magnan, and J.-B. Kim, "Do countries matter for voluntary disclosure? evidence from cross-listed firms in the US," Journal of International Business Studies, vol. 43, no. 2, pp. 143-165, 2012.

[23] I. Domowitz, J. Glen, and A. Madhavan, "Market segmentation and stock prices: evidence from an emerging market," The Journal of Finance, vol. 52, no. 3, pp. 1059-1085, 1997.

[24] H. Richard and V. Hooper, "Regionalism, political risk and capital market segmentation in international asset pricing," Journal of Economic Integration, vol. 16, no. 3, pp. 299-312, 2001.

[25] G. Bekaert and C. R. Harvey, "Foreign speculators and emerging equity markets," The Journal of Finance, vol. 55, no. 2, pp. 565-613, 2000.

[26] S. Li, N. Xu, and X. Hui, "International investors and the multifractality property: evidence from accessible and inaccessible market," Physica A: Statistical Mechanics and its Applications, vol. 559, Article ID 125029, 2020.

[27] M. N. Syllignakis and G. P. Kouretas, "Dynamic correlation analysis of financial contagion: evidence from the Central and Eastern European markets," International Review of Economics \& Finance, vol. 20, no. 4, pp. 717-732, 2011.

[28] Y. K. Tse and A. K. C. Tsui, "A multivariate generalized autoregressive conditional heteroscedasticity model with time-varying correlations," Journal of Business \& Economic Statistics, vol. 20, no. 3, pp. 351-362, 2002.

[29] I. A. Venetis and D. Peel, "Non-linearity in stock index returns: the volatility and serial correlation relationship," Economic Modelling, vol. 22, no. 1, pp. 1-19, 2005.

[30] P. Theodossiou, E. Kahya, G. Koutmos, and A. Christofi, "Volatility reversion and correlation structure of returns in major international stock markets," The Financial Review, vol. 32, no. 2, pp. 205-224, 1997.

[31] V. Fernandez, "Copula-based measures of dependence structure in assets returns," Physica A: Statistical Mechanics and its Applications, vol. 387, no. 14, pp. 3615-3628, 2008.

[32] S. Songsak, H. T. Nguyen, W. Aree et al., "Modeling volatility and dependency of agricultural price and production indices 
of Thailand: static versus time-varying copulas," International Journal of Approximate Reasoning, vol. 54, pp. 793-808, 2013.

[33] S. Sriboonchitta, J. Liu, V. Kreinovich, and H. T. Nguyen, "A Vine Copula approach for analyzing financial risk and comovement of the Indonesian, Philippine and Thailand stock markets," Modeling Dependence in Econometrics, vol. 251, pp. 245-257, 2014.

[34] S. I. Hussain and S. Li, "The dependence structure between Chinese and other major stock markets using extreme values and copulas," International Review of Economics \& Finance, vol. 56, pp. 421-437, 2018.

[35] B. Cha and S. Oh, "The relationship between developed equity markets and the Pacific Basin's emerging equity markets," International Review of Economics \& Finance, vol. 9, no. 4, pp. 299-322, 2000.

[36] R. Gupta and F. Guidi, "Cointegration relationship and time varying co-movements among Indian and Asian developed stock markets," International Review of Financial Analysis, vol. 21, pp. 10-22, 2012.

[37] P. Singh, B. Kumar, and A. Pandey, "Price and volatility spillovers across North American, European and Asian stock markets," International Review of Financial Analysis, vol. 19, no. 1, pp. 55-64, 2010.

[38] C. Walid, A. Chaker, O. Masood, and J. Fry, "Stock market volatility and exchange rates in emerging countries: a Markov-state switching approach," Emerging Markets Review, vol. 12, no. 3, pp. 272-292, 2011.

[39] B. H. Boyer, T. Kumagai, and K. Yuan, "How do crises spread? Evidence from accessible and inaccessible stock indices," The Journal of Finance, vol. 61, no. 2, pp. 957-1003, 2006.

[40] J. Kwapien and S. Drozdz, "Physical approach to complex systems," Physics Reports, vol. 515, pp. 115-226, 2012.

[41] B. B. Mandelbrot and J. W. Van Ness, "Fractional Brownian motions, fractional noises and applications," SIAM Review, vol. 10, no. 4, pp. 422-437, 1968.

[42] W. X. Zhou, "Multifractal detrended cross-correlation analysis for two nonstationary signals," Physical Review E, vol. 77, Article ID 066211, 2008.

[43] B. Podobnik, I. Grosse, D. Ilic, P. C. Ivanov, and H. E. Stanley, "Quantifying cross-correlations using local and global detrending approaches," The European Physical Journal B, vol. 71, no. 2, pp. 243-250, 2009.

[44] D. Ghosh, S. Dutta, and S. Chakraborty, "Multifractal detrended cross-correlation analysis of market clearing price of electricity and SENSEX in India," Physica A: Statistical Mechanics and Its Applications, vol. 434, pp. 52-59, 2015.

[45] Z. Song, Y. Chen, Y. Li et al., "An analysis of the allometric and multifractal features of a development in the urban-rural area in the lower reaches of the Yangtze river: 2012 crosssectional data of four Provinces and one city," Complexity, vol. 2020, Article ID 6963827, 19 pages, 2020.

[46] J. W. Kantelhardt, E. Koscielny-Bunde, D. Rybski et al., "Long-term persistence and multifractality of precipitation and river runoff records," Journal of Geophysical ResearchAtmospheres, vol. 111, no. D1, Article ID D01106, 2002.

[47] X. Zhao, P. Shang, A. Lin, and G. Chen, "Multifractal Fourier detrended cross-correlation analysis of traffic signals," Physica A: Statistical Mechanics and Its Applications, vol. 390, no. 2122, pp. 3670-3678, 2011.

[48] S. Shadkhoo and G. R. Jafari, "Multifractal detrended crosscorrelation analysis of temporal and spatial seismic data," The European Physical Journal B, vol. 72, no. 4, pp. 679-683, 2009.

[49] F. X. Diebold and K. Yilmaz, "Better to give than to receive: predictive directional measurement of volatility spillovers,"
International Journal of Forecasting, vol. 28, no. 1, pp. 57-66, 2012.

[50] F. X. Diebold and K. Y1lmaz, "On the network topology of variance decompositions: measuring the connectedness of financial firms," Journal of Econometrics, vol. 182, no. 1, pp. 119-134, 2014.

[51] Y. Yuan, X.-t. Zhuang, and X. Jin, "Measuring multifractality of stock price fluctuation using multifractal detrended fluctuation analysis," Physica A: Statistical Mechanics and its Applications, vol. 388, no. 11, pp. 2189-2197, 2009.

[52] H. H. Pesaran and Y. Shin, "Generalized impulse response analysis in linear multivariate models," Economics Letters, vol. 58, no. 1, pp. 17-29, 1998.

[53] G. Koop, M. H. Pesaran, and S. M. Potter, "Impulse response analysis in nonlinear multivariate models," Journal of Econometrics, vol. 74, no. 1, pp. 119-147, 1996.

[54] Y. Nishimura, Y. Tsutsui, and K. Hirayama, "Do international investors cause stock market spillovers? comparing responses of cross-listed stocks between accessible and inaccessible markets," Economic Modelling, vol. 69, pp. 237-248, 2018.

[55] G. M. Ljung and G. E. P. Box, "On a measure of lack of fit in time series models," Biometrika, vol. 65, no. 2, pp. 297-303, 1978.

[56] B. Podobnik, Z. Q. Jiang, W. X. Zhou et al., "Statistical tests for power-law cross-correlated processes," Physical Review E, vol. 84, pp. 066-118, 2011.

[57] W. Zhang, P. Wang, X. Li et al., "Multifractal detrended crosscorrelation analysis of the return-volume relationship of Bitcoin market," Complexity, vol. 2018, Article ID 8691420, 2018.

[58] F. Ma, Y. Wei, D. Huang et al., "Cross-correlations between West Texas intermediate crude oil and the Stock markets of the BRIC," Physica A: Statistical Mechanics and its Applications, vol. 392, pp. 5356-5368, 2013.

[59] W.-X. Zhou, "Finite-size effect and the components of multifractality in financial volatility," Chaos, Solitons \& Fractals, vol. 45, no. 2, pp. 147-155, 2012. 